\title{
Insulin sensitivity, insulin secretion and glucose effectiveness in diabetic and non-diabetic cirrhotic patients
}

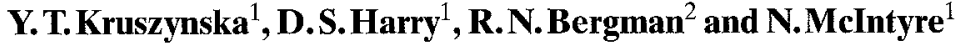 \\ ${ }^{1}$ Department of Medicine, Royal Free Hospital School of Medicine, London, UK and \\ ${ }^{2}$ Department of Physiology and Biophysics, University of Southern California School of Medicine, Los Angeles, California, USA
}

\begin{abstract}
Summary. In cirrhotic patients with normal fasting glucose levels both insulin insensitivity and a blunted early insulin response to oral glucose are important determinants of the degree of intolerance to oral glucose. It is not known whether the ability of hyperglycaemia per se to enhance glucose disposal (glucose effectiveness) is also impaired. It is also unclear whether overt diabetes is due to (1) more marked insulin insensitivity; (2) impaired insulin secretion; (3) reduced glucose effectiveness; or (4) a combination of these mechanisms. We used the "minimal model" to analyse the results of a 3 -h intravenous glucose tolerance test to assess glucose effectiveness, insulin sensitivity and insulin responses in 12 nondiabetic cirrhotic patients, 8 diabetic cirrhotic patients and 10 normal control subjects. Fasting blood glucose levels were $4.8 \pm 0.2,7.5 \pm 0.6$ and $4.7 \pm 0.1 \mathrm{mmol} / 1$, respectively. Fasting insulin and C-peptide levels were higher in both cirrhotic patient groups compared with control subjects. The glucose clearance between 6 and $19 \mathrm{~min}$ after i.v. glucose was lower in both cirrhotic groups (non-diabetic, $1.56 \pm 0.14$, diabetic, $0.76 \pm 0.06$, control subjects, $2.49 \pm 0.16 \mathrm{~min}^{-1} \%$, both $p<0.001$ vs control subjects). Serum insulin peaked at 3 and $23 \mathrm{~min}$ in the non-diabetic cirrhotic patients and control sub-
\end{abstract}

jects; both peaks were higher in the non-diabetic cirrhotic patients and showed a delayed return to basal levels. In the diabetic cirrhotic patients, the first phase insulin and C-peptide response to i.v. glucose was absent; their early (22$27 \mathrm{~min}$ ) incremental insulin response to $i$. v. tolbutamide was however similar to that of control subjects but $43 \%$ lower than in the non-diabetic cirrhotic patients $(p<0.05)$. Insulin sensitivity was markedly reduced in both cirrhotic groups (non-diabetic, $1.11 \pm 0.24 \times 10^{-4}$, diabetic, $0.33 \pm 0.53 \times 10^{-4}$, control subjects, $4.37 \pm 0.53 \times 10^{-4} \mathrm{~min}^{-1}$ per $\mathrm{mU} \cdot \mathrm{I}^{-1}$, both $p<0.001$ vs controls). Glucose effectiveness was normal in the non-diabetic cirrhotic patients but $29 \%$ lower in the diabetic group. It would appear that overt diabetes develops in those cirrhotic patients who in addition to insulin insensitivity have a marked impairment of insulin secretion. An associated reduction in glucose effectiveness may be a contributory factor.

Key words: Glucose intolerance, diabetes mellitus, cirrhosis, "minimal model", insulin, insulin sensitivity, insulin secretion, glucose effectiveness, tolbutamide.
Most cirrhotic patients are intolerant to oral glucose, even when their fasting blood glucose concentration is normal $[1,2]$. Overt diabetes mellitus is common. We recently showed, in cirrhotic patients with normal fasting blood glucose levels, that both insulin resistance and a relative impairment of insulin secretion are important determinants of the degree of oral glucose intolerance [3], as they are in Type 2 (non-insulin-dependent) diabetes $[4,5]$. In Type 2 diabetes, there is also an impairment of the ability of hyperglycaemia per se to promote tissue glucose utilisation and to inhibit hepatic glucose production $[5,6]$; this decrease in "glucose effectiveness" interacts synergistically with tissue insulin insensitivity and impaired islet beta-cell function to reduce glucose tolerance $[5,6]$. It is unclear whether progression to overt diabetes in patients with cirrhosis is due to (1) more marked insulin insensitivity, (2) to impaired insulin secretion; (3) to decreased glucose effectiveness, or (4) a combination of these mechanisms.

Bergman's "minimal model" [5-7] provides a measure of insulin sensitivity, glucose effectiveness and insulin secretion within the same study. Indices of insulin sensitivity $\left(\mathrm{S}_{\mathrm{I}}\right)$ and glucose effectiveness $\left(\mathrm{S}_{\mathrm{G}}\right)$ are calculated from computer analysis of blood glucose and serum insulin levels during a frequently-sampled i.v. glucose tolerance. test (FSIGT). The minimal model and the glucose clamp technique [8] provide an equivalent measure of insulin sensitivity in normal subjects [9]. The minimal model has been used to assess insulin sensitivity and glucose effectiveness in diabetes $[10,11]$, but not in cirrhosis. In this 
Table 1. Clinical characteristics of the cirrhotic patients and control subjects studied

\begin{tabular}{llll}
\hline & $\begin{array}{l}\text { Control } \\
\text { subjects }\end{array}$ & \multicolumn{2}{l}{ Cirrhotic patients } \\
\cline { 3 - 4 } & 10 & 12 & 8 \\
& & Non-diabetic Diabetic \\
\hline$n$ & $50 \pm 12$ & $52 \pm 11$ & $57 \pm 7$ \\
Age (years) & $70 \pm 10$ & $67 \pm 10$ & $75 \pm 11$ \\
Weight $(\mathrm{kg})$ & $24.2 \pm 2.7$ & $24.6 \pm 3.9$ & $25.6 \pm 3.4$ \\
BMI $\left(\mathrm{kg} / \mathrm{m}^{2}\right)$ & - & 9 & 5 \\
Oesophageal varices $(n)$ & & & \\
Oral hypoglycaemic agents: & & - & 6 \\
$\quad$ tolbutamide & - & - & 2 \\
$\quad$ glipizide & - & $35 \pm 6$ & $41 \pm 3$ \\
Albumin $(\mathrm{g} / \mathrm{l})$ & $41 \pm 3$ & $39 \pm 45$ & $33 \pm 35$ \\
Bilirubin $(\mu \mathrm{mol} / \mathrm{l})$ & $10 \pm 4$ & $16 \pm 1$ & $16 \pm 2$ \\
Prothrombin time $(\mathrm{s})$ & $13 \pm 1$ & & \\
\hline
\end{tabular}

Values are given as mean $\pm \mathrm{SD}$

study we used the minimal model to test the following hypotheses: (1) that glucose effectiveness would be relatively unaffected in cirrhotic patients with normal fasting glucose levels, but would be reduced in cirrhotic patients with overt diabetes (i.e. with fasting hyperglycaemia); (2) that diabetic cirrhotic patients would show an impairment of insulin secretion, or more marked insulin insensitivity or both, when compared with non-diabetic cirrhotic patients. As the minimal model has not been used previously in cirrhosis, we also examined the relationship between indices of insulin sensitivity derived from the minimal model and from a hyperinsulinaemic euglycaemic clamp.

\section{Subjects and methods}

We recruited 20 stable biopsy-proven cirrhotic patients with and without overt diabetes and 10 normal control subjects. The nondiabetic cirrhotic patients (nine alcoholic; three primary biliary) had a normal fasting blood glucose concentration; the diabetic cirrhotic patients (six alcoholic, two cryptogenic) were being treated with oral hypoglycaemic agents (Table 1) and all had a fasting blood glucose level while not being treated of greater than $6.6 \mathrm{mmol} / 1$. Clinical details are given in Table 1 . None of the patients or control subjects had a family history of diabetes and, apart from oral hypoglycaemic agents were not on treatment known to affect glucose tolerance. All were out-patients; their level of physical activity was similar to that of the control subjects. Five non-diabetic and three diabetic cirrhotic patients were taking spironolactone, but none had ascites at the time of study. Fourteen patients had oesophageal varices as seen on endoscopy; nine had previously bled from varices but not in the 3 months prior to study. Patients with alcoholic cirrhosis had abstained from alcohol for at least 1 month before study. The study was approved by the local ethical committee.

All patients and controls were studied on two occasions. Oral hypoglycaemic agents were discontinued 3 days before the study. All subjects had an oral glucose tolerance test and a frequently sampled i.v. glucose tolerance test (FSIGT). The non-diabetic cirrhotic patients and the control subjects also were studied during a hyperinsulinaemic euglycaemic clamp. The euglycaemic clamp data on seven of the cirrhotic patients and eight of the control subjects have been published previously [3]; their data is included in this study for comparison of the euglycaemic clamp and "minimal model" as measures of insulin sensitivity in cirrhosis. Euglycaemic clamp studies were not performed in the diabetic cirrhotic patients. Sup- pression of hepatic glucose output (HGO) during a glucose clamp may be impaired in diabetic cirrhotic patients [12]; we would therefore have had to infuse ${ }^{3} \mathrm{H}$-glucose to determine the contribution of residual HGO to total glucose disposal in these patients. All studies were performed after an overnight fast. For blood sampling, a venous cannula was inserted retrogradely in a hand vein, the hand being maintained in a hand warmer at $65^{\circ} \mathrm{C}$. After each blood sample, the sampling cannula was flushed with $0.15 \mathrm{~mol} / 1 \mathrm{NaCl}$ in water. For infusion of substances a second cannula was inserted in a vein in the antecubital fossa.

\section{Oral glucose tolerance tests}

Two basal blood samples were taken for estimation of blood glucose and serum insulin concentrations; subjects then ingested $75 \mathrm{~g}$ glucose in $390 \mathrm{ml}$ of water. The glucose was divided into five aliquots and was given at 1 -min intervals. Blood samples for glucose and insulin were taken at 15 -min intervals until $60 \mathrm{~min}$ and then at $30-\mathrm{min}$ intervals until $180 \mathrm{~min}$.

\section{Euglycaemic clamp studies}

After two basal blood samples were taken, for measurement of blood glucose and serum insulin concentrations, insulin (Humulin S; Eli Lilly, Basingstoke, UK) diluted in polygeline (Haemaccel; Hoechst, Frankfurt am Main, FRG) was infused i.v. at $0.1 \mathrm{U} \cdot \mathrm{kg}^{-1}$, $\mathrm{h}^{-1}$ using a syringe pump. Blood glucose was measured every $5 \mathrm{~min}$ and clamped at $4.0 \mathrm{mmol} / /$ for $2.5 \mathrm{~h}$ by adjustment of the rate of infusion of a solution of $20 \%$ (weight/volume) glucose in water [8]. Blood samples were taken at 30 -min intervals throughout the study for measurement of serum insulin.

\section{Frequently sampled $i . v$. glucose tolerance test (FSIGT)}

Four basal blood samples were taken over $20 \mathrm{~min}$. Then at $0 \mathrm{~min}$ $0.3 \mathrm{~g} / \mathrm{kg}$ glucose ( $50 \%$ glucose in water) was given within $1 \mathrm{~min}$ from a syringe pump. A bolus of tolbutamide $(300 \mathrm{mg})$ was given i.v. at $20 \mathrm{~min}$. The use of tolbutamide to augment and prolong the insulin secretory response has been shown to improve the precision of $S_{I}$ estimated by the minimal model [13]. Blood samples for measurement of blood glucose and serum insulin were taken at the following times after glucose injection: $2,3,4,5,6,8,10,12,14,16,19,22,23,24$, $25,27,30,40,50,60,70,80,90,100,120,140,160$ and $180 \mathrm{~min}$, and for serum C-peptide at 3, 4, 19,23 and 24 min after i.v. glucose. The peak serum C-peptide responses to the i.v. glucose and tolbutamide are presented as the average of the C-peptide levels in the 3-and 4-min samples and the 23- and 24-min samples, respectively.

\section{Assays}

Blood glucose was measured by a glucose oxidase method (Yellow Springs glucose analyser; Clandon Scientific, London, UK). Serum insulin was measured using a double antibody technique [14]; the intra- and inter-assay coefficients of variation were $6.8 \%$ and $7.9 \%$, respectively. Serum C-peptide was measured by ethanol precipitation radioimmunoassay [15] using the M1221 antibody and a synthetic standard (Novo Research Institute, Bagsvaerd, Denmark).

\section{Calculations}

Intravenous glucose tolerance $\left(\mathrm{K}_{\mathrm{G}}\right)$ was calculated as the slope of the regression of the logarithm of blood glucose concentration against time between 6 and $19 \mathrm{~min}$ after i.v. glucose administration. $S_{I}$ and $S_{G}$ were calculated from the FSIGT results using the computer program 

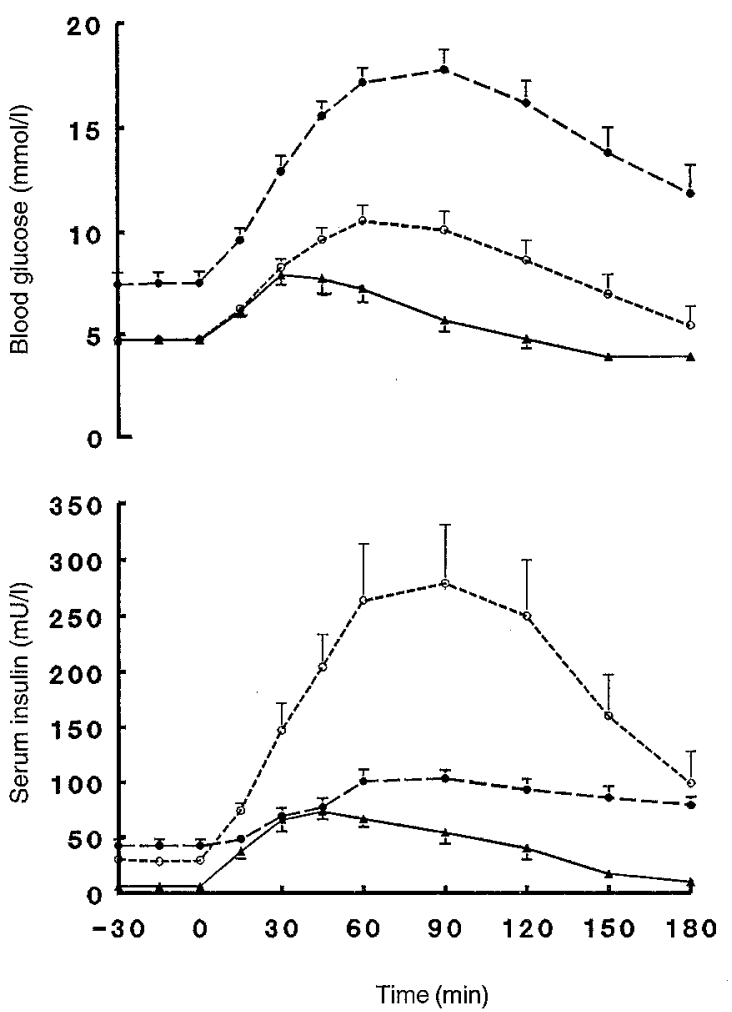

Fig. 1. Blood glucose and serum insulin responses to a $75 \mathrm{~g}$ oral glucose load in 12 non-diabetic cirrhotic patients $(0-\cdots), 8$ diabetic cirrhotic patients $(\bullet-\bullet)$, and 10 normal control subjects $(\llcorner\mathbf{\Lambda})$. Mean \pm SEM

MINMOD (copyright R.N. Bergman). Details of the analysis have been presented previously [9]. Briefly, the minimal model of glucose kinetics describes the relationship between serum insulin levels during the FSIGT and the decline in the blood glucose concentration after i. v. glucose. The model assumes: (1) that glucose inhibits HGO and increases tissue glucose utilisation in proportion to its concentration in plasma [16-19]; (2) that insulin enhances these effects of glucose; and (3) that the effect of insulin to promote glucose disappearance from plasma depends on the concentration of insulin in a compartment remote from plasma $[20,21]$. These assumptions are represented by the following two equations of the minimal model:

$\mathrm{dG}(\mathrm{t}) / \mathrm{dt}=-\left[\mathrm{p}_{1}+\mathrm{X}(\mathrm{t})\right] \mathrm{G}(\mathrm{t})+\mathrm{p}_{1} \mathrm{G}_{\mathrm{b}}$

$\mathrm{dX}(\mathrm{t}) / \mathrm{dt}=-\mathrm{p}_{2} \mathrm{X}(\mathrm{t})+\mathrm{p}_{3}\left[\mathrm{I}(\mathrm{t})-\mathrm{I}_{\mathrm{b}}\right]$

where $G(t)$ and $I(t)$ are plasma glucose and insulin concentrations at time $t$, and $G_{b}$ and $I_{b}$ are the basal concentrations of glucose and insulin prior to the glucose bolus. The variable $X(t)$ is the accelerating effect of insulin on glucose disappearance from plasma, and is proportional to the concentration of insulin in a compartment remote from plasma. Parameters $p_{1}, p_{2}$, and $p_{3}$ are model parameters that are estimated from least squares fitting of the glucose data.

Parameter $p_{1}$ represents the ability of glucose per se to lower its own concentration independent of a rise in insulin. This effect is termed "glucose effectiveness" $\left(S_{G}\right)$, with units $\min ^{-1}$. $S_{I}$ is the increase in fractional glucose disappearance rate (i.e. glucose effectiveness) per unit increase in plasma insulin $\left(\min ^{-1}\right.$ per $\left.\mathrm{mU} \cdot \mathrm{l}^{-1}\right)$ and is equal to the ratio $\left(\mathrm{p}_{3} / \mathrm{p}_{2}\right)$.

\section{Statistical analysis}

Results are expressed as mean \pm SEM unless otherwise indicated. Areas under the glucose and insulin concentration curves were calculated by the trapezoidal rule. Correlations were sought by Pear- son's least squares method. The significance of differences between groups was tested by Student's paired or unpaired $t$-test or by analysis of variance (ANOVA) followed by Tukey's multiple comparison test, as appropriate. A $p$ value of less than 0.05 was considered statistically significant.

\section{Results \\ Oral glucose tolerance tests}

Fasting blood glucose concentrations did not differ between non-diabetic cirrhotic patients and control subjects $(4.8 \pm 0.2$ vs $4.7 \pm 0.1 \mathrm{mmol} / \mathrm{l})$ but were significantly higher in the diabetic cirrhotic patients $(7.5 \pm 0.6 \mathrm{mmol} / \mathrm{l}$, $p<0.001)$. Fasting serum insulin levels were higher in both cirrhotic groups (non-diabetic, $29.3 \pm 2.9$, diabetic, $42.4 \pm 5.6 \mathrm{mmol} / \mathrm{l})$ compared to control subjects $(5.9 \pm$ $1.1 \mathrm{mU} / 1)(p<0.001$ for both $)$ and significantly higher in the diabetic than in the non-diabetic patients $(p<0.05)$. Following oral glucose, blood glucose concentrations were significantly higher in both cirrhotic groups than in control subjects, and much higher in diabetic than in the non-diabetic cirrhotic patients (Fig.1); serum insulin levels were markedly increased in the non-diabetic patients and remained elevated until $180 \mathrm{~min}$ (Fig.1). In the diabetic cirrhotic patients, the increase in serum insulin levels was delayed (Fig.1); the incremental area under the $3 \mathrm{~h}$ serum insulin concentration curve (AUC) $\left(126 \pm 18 \mathrm{mU} \cdot 1^{-1} \cdot \mathrm{h}^{-1}\right)$ was markedly reduced compared to that of non-diabetic cirrhotic patients $(579 \pm 90 \mathrm{mU}$. $\left.\mathrm{l}^{-1} \cdot \mathrm{h}^{-1}\right)(p<0.001)$ but it was not significantly different from that of control subjects $\left(110 \pm 15 \mathrm{mU} \cdot \mathrm{I}^{-1} \cdot \mathrm{h}^{-1}\right)$.

\section{Frequently sampled i.v. glucose tolerance tests (FSIGT)}

After i.v. glucose, blood glucose levels in non-diabetic cirrhotic patients and control subjects were similar at the initial peak (non-diabetic cirrhotic patients, $14.8 \pm$ $0.4 \mathrm{mmol} / \mathrm{l}$; control subjects, $15.6 \pm 1.3 \mathrm{mmol} / \mathrm{l}$ ) and at later time points (Fig.2). However, glucose tolerance, as reflected by the $\mathrm{K}_{\mathrm{G}}$ between 6 and $19 \mathrm{~min}$, was impaired (non-diabetic cirrhotic patients, $1.56 \pm 0.14$; control subjects, $2.49 \pm 0.16 \% \mathrm{~min}^{-1}, p<0.001$ ). In the diabetic cir-

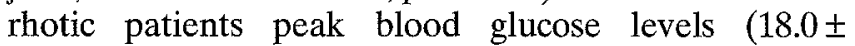
$0.6 \mathrm{mmol} / 1)$ after i.v. glucose were higher than in both non-diabetic cirrhotic patients and control subjects and remained significantly higher until $180 \mathrm{~min}$ (Fig.2); their $\mathrm{K}_{\mathrm{G}}$ between 6 and 19 min was markedly reduced ( $0.76 \pm$ $0.06 \% \min ^{-1}, p<0.001$ vs both control subjects and nondiabetic cirrhotic patients). There was a good correlation between $\mathrm{K}_{\mathrm{G}}$ and the area under the blood glucose concentration curve after oral glucose in the two cirrhotic groups combined $(r=-0.809, p<0.001)$ and in the control subjects $(r=-0.775, p<0.01)$ (Fig. 3$)$; in the cirrhotic patients there was also a good relationship with the $2 \mathrm{~h}$ blood glucose level after oral glucose $(r=-0.812, p<0.001)$.

In the control subjects and non-diabetic cirrhotic patients serum insulin levels peaked at $3 \mathrm{~min}$ after i.v. glucose (first phase insulin response); a second peak was ob- 

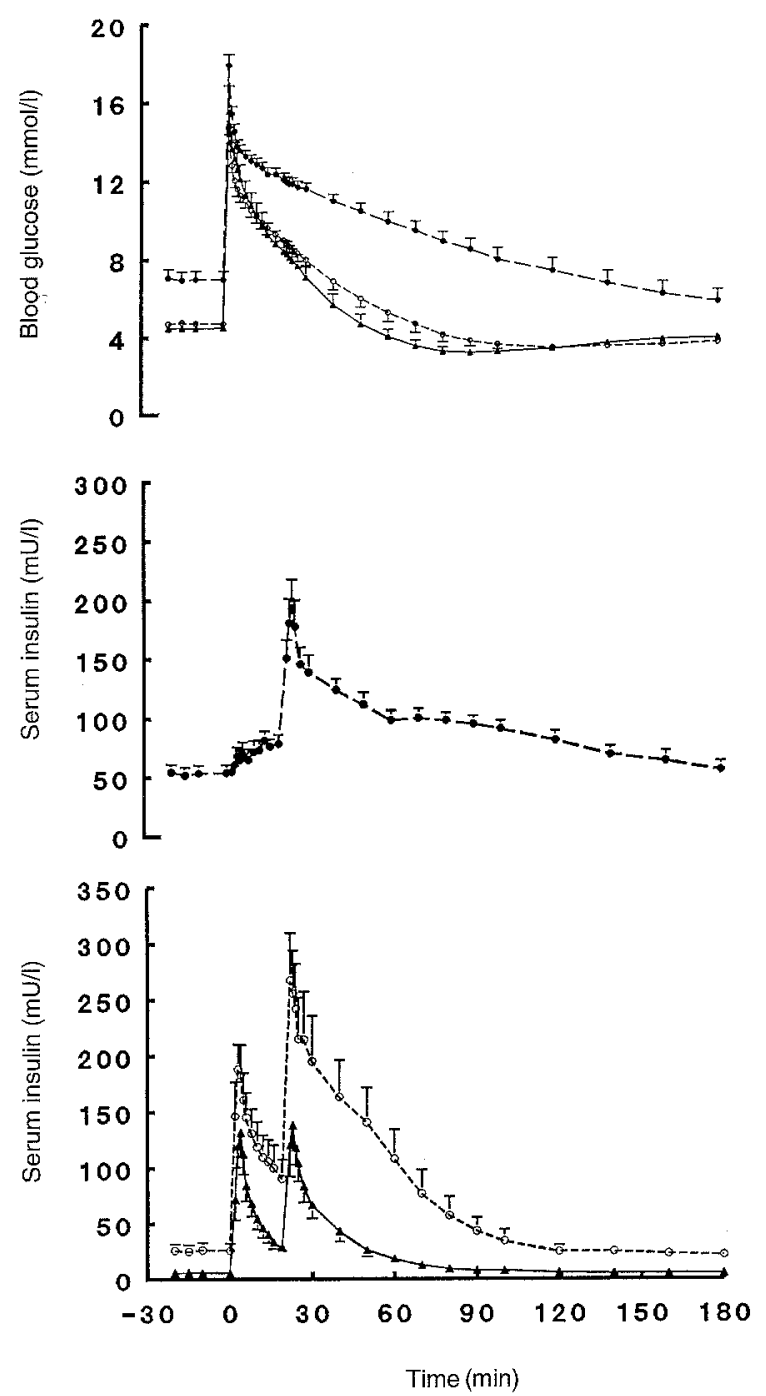

Fig. 2. Blood glucose and serum insulin levels after i.v. glucose $(0.3 \mathrm{~g} / \mathrm{kg})$ at $\mathrm{t}=0 \mathrm{~min}$ and $\mathrm{i}$. v. tolbutamide $(300 \mathrm{mg})$ at $\mathrm{t}=20 \mathrm{~min}$ in 12 non-diabetic cirrhotic patients (O---O), 8 diabetic cirrhotic patients (---), and 10 normal control subjects $(-)$. Mean \pm SEM

served at $23 \mathrm{~min}$ (i.e. following the i.v. tolbutamide). In the non-diabetic cirrhotic patients both insulin peaks were higher and the decline in serum insulin levels was more gradual than in control subjects (Fig.2). The serum insulin AUC during the first 6 min after $i$. v. glucose was greater in the non-diabetic cirrhotic patients than in control subjects $\left(851 \pm 115\right.$ vs $\left.520 \pm 88 \mathrm{mU} \cdot \mathrm{l}^{-1} \cdot \mathrm{min}^{-1}, p<0.05\right)$. However, because cirrhotic patients had higher basal insulin levels, the difference in the incremental insulin AUC during the first $6 \mathrm{~min}$, although greater in the non-diabetic cirrhotic patients, did not reach statistical significance (Table 2). The first 3-4 min C-peptide peak was not different in the two groups (non-diabetic cirrhotic patients, $2.16 \pm 0.37$; control subjects, $2.33 \pm 0.19 \mathrm{nmol} / \mathrm{l}$ ). In the diabetic cirrhotic patients the first phase insulin response was absent (Fig.2; Table 2) and the 3-4 min C-peptide level showed only a small increase from basal $(1.21 \pm 0.11$ vs $1.03 \pm 0.10 \mathrm{nmol} / \mathrm{l})$. Insulin levels in this group increased gradually from a basal level of $54 \pm 6 \mathrm{mU} / 1$ to $79 \pm 7 \mathrm{mU} / 1$ at $19 \mathrm{~min}$. In the combined cirrhotic groups $(n=20)$ and the control subjects $\mathrm{K}_{\mathrm{G}}$ was strongly related to the incremental first phase insulin response after i.v. glucose (Fig. 4; cirrhotic patients; $r=0.797$; control subjects, $r=0.877$, both $p<0.001$ ).

After i.v. tolbutamide, the $22-27 \mathrm{~min}$ incremental insulin AUC in the non-diabetic cirrhotic patients was twice that of control subjects (Table $2, p<0.05$ ) but the incremental 23-24 min C-peptide response not different. By contrast, the diabetic cirrhotic patients had an incremental 22-27 min insulin response similar to that of control subjects but $43 \%$ lower than in the non-diabetic cirrhotic patients (Table 2, $0.05<p<0.1$ ). Their incremental 2324 min C-peptide response tended to be lower than in control subjects and non-diabetic cirrhotic patients (Table 2) but the difference was not statistically significant. The integrated $22-180 \mathrm{~min}$ insulin response above basal was similar in the two cirrhotic groups (Table 2); in both cirrhotic groups it was more than three times that observed in the control subjects (Table 2).

$\mathrm{S}_{\mathrm{I}}$ was markedly decreased in both cirrhotic groups (non-diabetic, $1.11 \pm 0.24 \times 10^{-4}$; diabetic, $0.33 \pm 0.53 \times$ $10^{-4}$; control subjects, $4.37 \pm 0.53 \times 10^{-4} \mathrm{~min}^{-1}$ per $\mathrm{mU}$. $1^{-1}, p<0.001$ for both cirrhotic groups vs control subjects). $\mathrm{S}_{\mathrm{G}}$ did not differ between non-diabetic cirrhotic patients $\left(0.0213 \pm 0.0019 \mathrm{~min}^{-1}\right)$ and control subjects $(0.0205 \pm$ $\left.0.0011 \mathrm{~min}^{-1}\right)$ but was lower in the diabetic cirrhotic patients $\left(0.0146 \pm 0.0018 \mathrm{~min}^{-1}\right)(p<0.05$ vs non-diabetic cirrhotic patients; $0.05<p<0.1$ vs control subjects).

In both the cirrhotic patients $(n=20)$ and control subjects, $K_{G}$ after i.v. glucose was related to $S_{G}$ (Fig. 5; $r=0.471$ and $r=0.659$ respectively, $p<0.05$ for both), but not significantly to $\mathrm{S}_{\mathrm{I}}$ (cirrhotic patients, $r=0.383$, control subjects, $r=0.06$ ). The area under the 3 -h blood glucose curve after oral glucose was however inversely related to $\mathrm{S}_{\mathrm{I}}$ in the cirrhotic patients $(r=-0.482, p<0.05)$ but not in the control subjects.

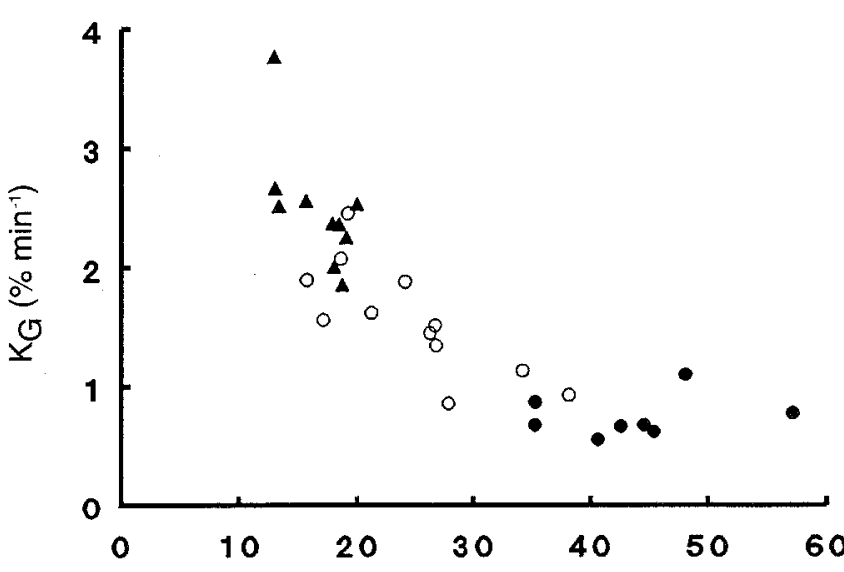

Glucose AUC after oral glucose $\left(\mathrm{mmol} \cdot{ }^{-1} \cdot \mathrm{h}^{-1}\right)$

Fig. 3. The relationship between glucose clearance $\left(\mathrm{K}_{\mathrm{G}}\right)$ during the frequently-sampled i.v.glucose tolerance test and the area under the blood glucose concentration curve (AUC) after oral glucose in 12 non-diabetic cirrhotic patients (O), 8 diabetic cirrhotic patients (•) and 10 normal control subjects ( $\boldsymbol{\Delta}$ ). There was a strong relationship between these two measures of glucose tolerance in both the control subjects $(r=-0.78, p<0.01)$ and the cirrhotic patients $(n=20)(r=-0.81, p<0.001)$ 
Table 2. Serum insulin and C-peptide responses during the frequently-sampled i.v. glucose tolerance test (FSIGT) in the cirrhotic patients and control subjects. Glucose $(0.3 \mathrm{~g} / \mathrm{kg}$ i.v. $)$ was given at $0 \mathrm{~min}$; tolbutamide ( $300 \mathrm{mg}$ i.v.) was given at $20 \mathrm{~min}$

\begin{tabular}{llll}
\hline & $\begin{array}{l}\text { Control } \\
\text { subjects }\end{array}$ & \multicolumn{2}{l}{ Cirrhotic patients } \\
\cline { 3 - 4 } & 10 & Non-diabetic & Diabetic \\
\hline$n$ & & & 8 \\
Fasting & & & \\
Insulin (mU/l) & $5.9 \pm 0.8$ & $26.0 \pm 6.1^{\mathrm{a}}$ & $53.8 \pm 6.3^{\mathrm{c}, \mathrm{e}}$ \\
C-peptide (nmol/l) & $0.41 \pm 0.04$ & $0.68 \pm 0.10^{\mathrm{a}}$ & $1.03 \pm 0.10^{\mathrm{c}, \mathrm{d}}$
\end{tabular}

FSIGT

Incremental insulin-AUC $\left(m U \cdot l^{-1}\right.$ min $)$

$\begin{array}{lccc}0-6 \min & 485 \pm 85 & 695 \pm 108 & 43 \pm 19^{\mathrm{b}, \mathrm{f}} \\ 22-27 \mathrm{~min} & 529 \pm 76 & 1039 \pm 172^{\mathrm{a}} & 595 \pm 96 \\ 22-180 \mathrm{~min} & 1864 \pm 380 & 6760 \pm 1361^{\mathrm{b}} & 6095 \pm 709^{\mathrm{a}}\end{array}$

Incremental serum C-peptide ( $\mathrm{nmol} / \mathrm{l}$ )

\begin{tabular}{llll}
$3-4 \mathrm{~min}$ & $1.92 \pm 0.19$ & $1.48 \pm 0.28$ & $0.19 \pm 0.04^{\mathrm{c}, \mathrm{f}}$ \\
$23-24 \mathrm{~min}$ & $1.72 \pm 0.26$ & $1.81 \pm 0.30$ & $1.26 \pm 0.30$ \\
\hline
\end{tabular}

${ }^{\mathrm{a}} p<0.05,{ }^{\mathrm{b}} p<0.01,{ }^{\mathrm{c}} p<0.001$ compared with normal control subjects, ${ }^{\mathrm{d}} p<0.05$, ${ }^{\mathrm{e}} p<0.005$, ${ }^{\mathrm{f}} p<0.001$ compared with nondiabetic cirrhotic patients. Values are given as mean \pm SEM

AUC, area under concentration curve

\section{Euglycaemic clamp}

During the euglycaemic clamp steady-state serum insulin levels were higher in the non-diabetic cirrhotic patients $(184 \pm 13 \mathrm{mU} / \mathrm{l})$ than in control subjects $(132 \pm 5 \mathrm{mU} / \mathrm{l})$ $(p<0.002)$. The glucose requirement to maintain the clamp during the period $120-150 \mathrm{~min}$ was lower in the non-diabetic cirrhotic patients $\left(4.79 \pm 0.34 \mathrm{mg} \cdot \mathrm{kg}^{-1}\right.$. $\min ^{-1}$ vs $\left.8.05 \pm 0.46 \mathrm{mg} \cdot \mathrm{kg}^{-1} \cdot \mathrm{min}^{-1}, p<0.001\right)$. There was a more rapid increase in glucose requirement to maintain euglycaemia during the clamp in control subjects than in the non-diabetic cirrhotic patients. The time required to reach $75 \%$ of the steady-state glucose requirement was $43 \pm 3 \mathrm{~min}$ in control subjects compared to $61 \pm 6 \mathrm{~min}$ in the non-diabetic cirrhotic patients $(p<0.05)$.

There was a strong correlation between $\mathrm{S}_{\mathrm{I}}$ derived from the minimal model and the clamp glucose requirement per $100 \mathrm{mU} \cdot 1^{-1}$ of serum insulin (Fig.6; non-diabetic cirrhotic patients, $r=0.902, p<0.001$; control subjects, $r=0.750, p<0.02)$. The slopes of the regression lines relating these two indices of insulin sensitivity were not significantly different between non-diabetic cirrhotic patients $(0.631 \pm 0.096)$ and control subjects $(0.748 \pm 0.233)$.

\section{Discussion}

Several studies have suggested that in cirrhosis, intolerance to oral glucose is more frequent and more pronounced than intolerance to i.v. glucose $[1,2]$. Conn et al. [2] found abnormal oral glucose tolerance tests in $80 \%$ of 145 cirrhotic patients but abnormal i.v. glucose tolerance (defined as a 2-h serum glucose above $7.8 \mathrm{mmol} / \mathrm{l}$ after $25 \mathrm{~g}$ i.v. glucose) in only $19 \%$ of these patients. There was less discrepancy if the i.v. glucose tolerance data were expressed in terms of glucose clearance $\left(\mathrm{K}_{\mathrm{G}}\right)$, which was ab- normal in $68 \%$ of their patients [2]. In our non-diabetic cirrhotic patients, with relatively mild intolerance to oral glucose we found a $37 \%$ decrease in $\mathrm{K}_{\mathrm{G}}$, which was inversely correlated with the 3 -h area under the blood glucose curve after oral glucose $(r=-0.77, p<0.005)$. In diabetic cirrhotic patients, $\mathrm{K}_{\mathrm{G}}$ was decreased by $70 \%(p<0.001)$; seven of these eight patients had a $\mathrm{K}_{\mathrm{G}}$ less than 1.0 consistent with a diagnosis of diabetes [22,23]. Considering both cirrhotic groups together there was a very good correlation between $\mathrm{K}_{\mathrm{G}}$ and the blood glucose AUC after oral glucose $(r=-0.81, p<0.001)$. These results suggest that the higher prevalence of oral glucose intolerance (compared to i.v.) in cirrhosis may have been overemphasised; the prevalence depends partly on the criteria chosen to define glucose intolerance.

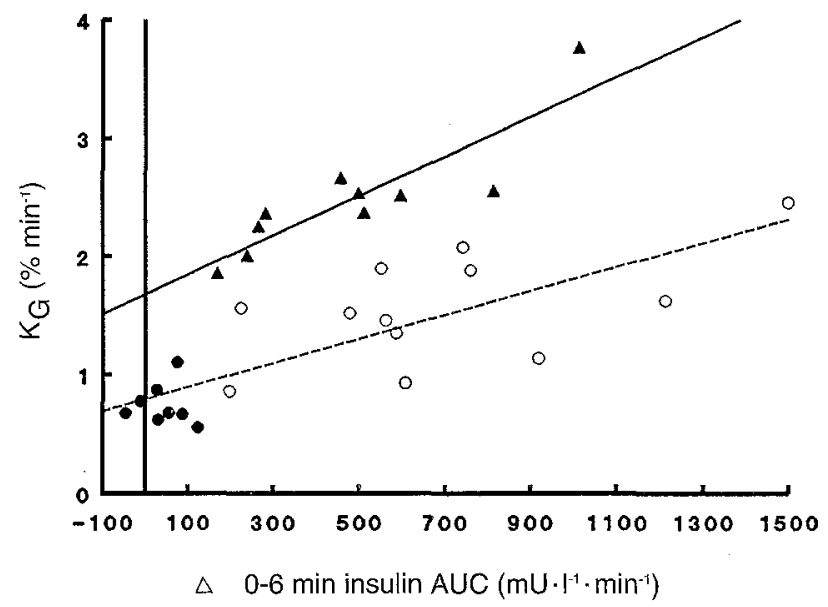

Fig.4. The relationship between glucose clearance $\left(K_{G}\right)$ during the frequently-sampled i.v. glucose tolerance test and the incremental area under the 0-6 min serum insulin concentration curve (AUC) after i.v. glucose in 12 non-diabetic cirrhotic patients $(O), 8$ diabetic cirrhotic patients (O) and 10 normal control subjects $(\boldsymbol{A})$. There was a strong relationship between these two variables in both the control subjects $(r=0.873, p<0.001)$ and the cirrhotic patients $(n=20)(r=0.797, p<0.001)$

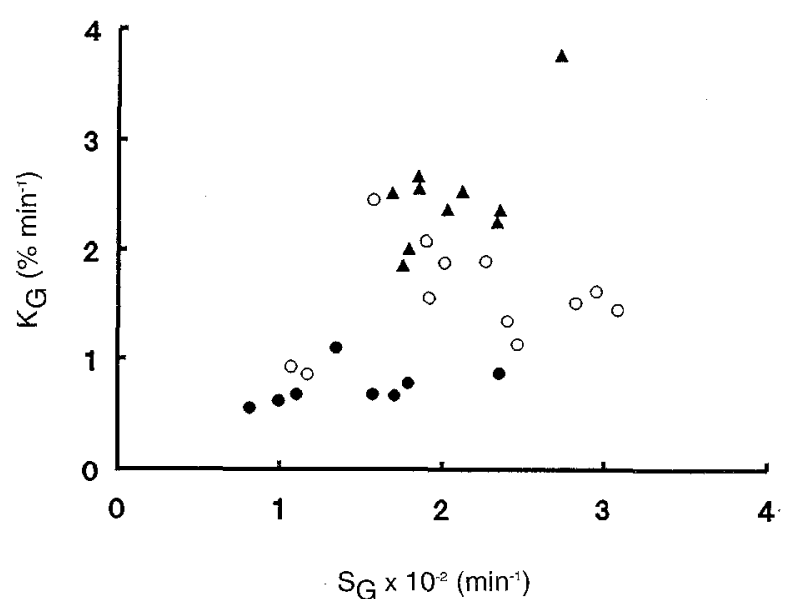

Fig.5. The relationship between glucose clearance $\left(K_{G}\right)$ during the frequently-sampled i.v. glucose tolerance test and glucose effectiveness $\left(\mathrm{S}_{\mathrm{G}}\right)$ in 12 non-diabetic cirrhotic patients $(0), 8$ diabetic cirrhotic patients ( $)$ and 10 normal control subjects $(\mathbf{A})$. There was a significant relationship in both the control subjects $(r=0.66$, $p<0.05)$ and cirrhotic patients $(n=20)(r=0.47, p<0.05)$ 


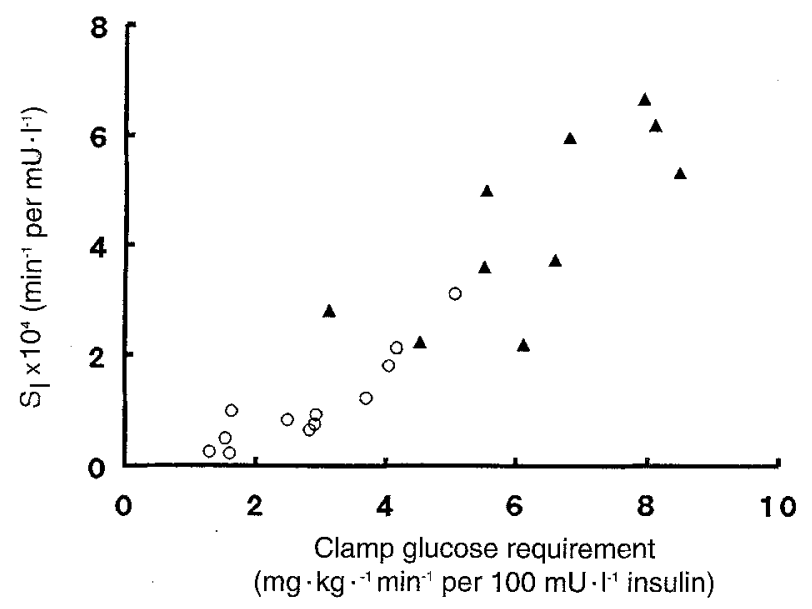

Fig. 6. The relationship between the insulin sensitivity index $\left(S_{I}\right)$ from the minimal model analysis of the frequently-sampled i.v. glucose tolerance test and insulin sensitivity as measured by the euglycaemic clamp in 12 non-diabetic cirrhotic patients $(O)$ and 10 control subjects $(\boldsymbol{\Delta})$. In both gxoups there was a strong relationship between these two estimates of insulin sensitivity (cirrhotic patients, $r=0.902, p<0.001 ;$ control subjects $r=0.750, p<0.02$ )

Fasting insulin levels were increased five-fold in the non-diabetic cirrhotic patients and nine-fold in the diabetic cirrhotic patients. Interpretation of peripheral insulin levels in cirrhosis is complicated by their reduced hepatic insulin extraction $[3,24]$. C-peptide which is co-secreted with insulin in equimolar amounts but not extracted by the liver provides a much better index of insulin secretion [25]. In our non-diabetic cirrhotic patients fasting C-peptide was increased 1.7-fold suggesting that both hypersecretion and decreased clearance contribute to the basal hyperinsulinaemia, with reduced insulin clearance being quantitatively the more important. The higher fasting $\mathrm{C}$-peptide levels in the diabetic group suggests that increased insulin secretion accounts for the further increase in fasting insulin levels compared to the nondiabetic cirrhotic patients.

In the non-diabetic cirrhotic patients insulin levels were also higher after both i.v. glucose and tolbutamide. Their C-peptide responses (both peaks) were however similar to those of control subjects suggesting that the higher insulin levels during the FSIGT were due to reduced insulin clearance. In the control subjects, the incremental insulin and C-peptide responses to glucose and tolbutamide were similar. By contrast, in the non-diabetic cirrhotic patients the early incremental insulin response to tolbutamide was 1.5 -fold that seen following the i.v. glucose bolus $(p<0.05)$ and nearly twice that of control subjects $(p<0.05)$. However, their incremental C-peptide responses to glucose and tolbutamide were not significantly different. Our previous studies $[3,26]$ and that of Tillil et al. [27] suggested that first pass hepatic extraction of insulin falls at high rates of insulin secretion. Thus, the greater insulin response to tolbutamide compared to i.v. glucose, in the non-diabetic cirrhotic patients could be due in part to a fall in hepatic insulin extraction, since insulin levels at $20 \mathrm{~min}$ were three times higher than in the basal state.
The most striking abnormality was the complete loss of first phase insulin and C-peptide responses to i.v. glucose in the diabetic cirrhotic patients, but relative preservation of the insulin and C-peptide responses to i. v. tolbutamide. This finding is similar to that seen in patients with Type 2 diabetes [28-30]. Brunzell et al. [23] reported a complete loss of first phase insulin responses in subjects with a fasting blood glucose above $6.4 \mathrm{mmol} / 1$. The mechanisms for this loss of the first phase insulin response to glucose, but preservation of the early insulin response to other secretagogues in diabetes (at least in the early stages), is unknown. Given the higher blood glucose level at $20 \mathrm{~min}$ in the diabetic cirrhotic patients, the insulin and C-peptide responses to tolbutamide may be considered to be subnormal. A reduction in islet beta-cell mass or in the quantity of insulin available for rapid release could explain the blunted insulin response to tolbutamide. However, the striking contrast between the response to glucose and tolbutamide in these patients seems to imply a specific defect in the ability of islet beta cells to sense glucose, in addition to any decrease in beta-cell number or diminished capacity for insulin synthesis.

The finding of reduced $S_{G}$ in diabetic cirrhotic patients, is in keeping with the reductions in $S_{G}$ found in both Type 1 (insulin-dependent) $[10,11]$ and Type 2 diabetic patients $[5,6] . \mathrm{S}_{\mathrm{G}}$ was normal in the non-diabetic cirrhotic patients, which helps to explain their relatively good i.v. glucose tolerance and their normal rates of glucose disposal under hyperglycaemic clamp conditions $[3,31]$, although in the latter situation interpretation is complicated by the striking increase in plasma insulin levels [3]. $\mathrm{S}_{\mathrm{G}} \mathrm{de}-$ pends on the inhibitory effect of the plasma glucose level on HGO as well as on its mass action effect on peripheral glucose uptake [32]. Therefore, impaired suppression of HGO could account for the $29 \%$ reduction in $S_{G}$ in our diabetic cirrhotic patients. Another possible explanation for the reduction in $S_{G}$ is a depletion of tissue glucose transporters, or a reduction in their activity as hyperglycaemia causes a depletion of the insulin-regulated glucose transporter (GLUT 4) in skeletal muscle [33]; thus chronic hyperglycaemia rather than a primary genetic abnormality may be responsible for the lower $\mathrm{S}_{\mathrm{G}}$ in diabetic patients. The normal $S_{G}$ in non-diabetic cirrhotic patients is consistent with this hypothesis.

One would expect $K_{G}$ to be related to both $S_{G}$, and also to first phase insulin response, as a prompt insulin secretory response is important for normal tolerance to $\mathrm{i}$. $\mathrm{v}$. glucose $[34,35]$ as well as to oral glucose $[34,36,37]$. In keeping with earlier reports [38] we found a good correlation between the 6-19 $\min \mathrm{K}_{\mathrm{G}}$ value and the incremental first phase insulin response to glucose in both control subjects $(r=0.873, p<0.001)$ and the combined cirrhotic patient groups $(r=0.797, p<0.001)$. It is unlikely that this relationship simply reflects the effect of insulin on peripheral tissues, as there is a substantial delay between an increase in plasma insulin and the effect of this increase on glucose disposal $[20,21,39]$. Although, there was a significant relationship between $\mathrm{K}_{\mathrm{G}}$ and $\mathrm{S}_{\mathrm{G}}$ in the control subjects and in the two cirrhotic groups combined, this was not as striking as the relationship between $K_{G}$ and the incremental first phase insulin response to glucose. The re- 
lationship between $\mathrm{K}_{\mathrm{G}}$ and both the incremental first phase insulin response to glucose and $\mathrm{S}_{\mathrm{G}}$ may be explained by an effect on HGO. There is evidence that suppression of HGO contributes substantially to the early decline in plasma glucose levels after i.v. glucose [32], and an early insulin response is important for this suppression of $\mathrm{HGO}$ [35]. In normal subjects inhibition of first phase insulin secretion during i.v. glucose infusion reduced the suppression of HGO by nearly $50 \%$, but was without effect on tissue glucose uptake [35]. Hyperglycaemia itself suppresses HGO but only if there is adequate basal hepatic insulinisation; complete suppression depends on a concomitant increase in hepatic insulin delivery [40]. Fasting hyperglycaemia in Type 2 diabetes [41] and diabetic cirrhotic patients [12] is due mainly to increased basal HGO implying inadequate basal hepatic insulin delivery in our diabetic cirrhotic patients. In the absence of an acute insulin response to i.v. glucose one would expect an impairment of suppression of HGO following i.v. glucose and this would result in a lower $S_{G}$.

The delay between a rise in plasma insulin and the effect of this rise on glucose metabolism $[20,21,39]$ is thought to be due mainly to the time required to transport insulin into the interstitial space. In dogs the rate of glucose utilisation correlates better with changes in lymph insulin (thought to be representative of interstitial insulin) than with changes in plasma insulin concentration [42]. In this and our previous study [43] we found a slower increase in clamp glucose requirement in cirrhotic patients. A similar defect has been reported in obese subjects [44]. This dynamic component of insulin insensitivity would clearly be important under physiological conditions, e.g. during meals, when hyperinsulinaemia may not persist long enough to attain steady-state at its site of action. The index of insulin sensitivity based on steady-state glucose requirements during the euglycaemic clamp does not take into account the dynamic component of insulin insensitivity and may thus underestimate the real degree of insulin insensitivity present in cirrhotic tissues.

In the current study insulin sensitivity was measured both by the euglycaemic clamp and by the minimal model method. The insulin infusion rate used during the euglycaemic clamp was considerably higher than that shown to completely suppress HGO in both control subjects and non-diabetic cirrhotic patients $[45,46]$. Both methods confirmed the presence of marked insulin resistance in the non-diabetic cirrhotic patients and there was a strong correlation between indices of insulin sensitivity derived by the two methods, suggesting that the minimal model provides a useful measure of insulin sensitivity in cirrhosis. However, whereas $S_{I}$ in the non-diabetic cirrhotic patients was only $25 \%$ of that in control subjects $\left(1.11 \pm 0.24 \times 10^{-4}\right.$ vs $4.37 \pm 0.53 \times 10^{-4} \mathrm{~min}^{-1}$ per mU $\cdot 1^{-1}$, $p<0.001$ ), clamp glucose requirement per $100 \mathrm{mU} \cdot 1^{-1}$ insulin was reduced to a lesser extent $(2.84 \pm 0.35$ vs $6.27 \pm$ $0.53 \mathrm{mg} \cdot \mathrm{kg}^{-1} \cdot \mathrm{min}^{-1}$ per $\left.100 \mathrm{mU} \cdot \mathrm{l}^{-1}, p<0.001\right)$. The minimal model, by contrast with the euglycaemic clamp, takes into account the delay in the onset of insulin action, by assuming that the efffects of insulin on glucose metabolism are related to the concentration of insulin in a compartment remote from plasma. An impairment of insulin transport into, or an increase in the removal of insulin from, this compartment would lower $S_{\mathrm{I}}$. Thus, the more profound defect in $\mathrm{S}_{\mathrm{I}}$, when compared to the euglycaemic clamp index of insulin sensitivity, is probably due to the dynamic defect in insulin action in the cirrhotic patients. Another possible explanation for the lower $\mathrm{S}_{\mathrm{I}}$ compared to the clamp index of insulin sensitivity is decreased clearance of insulin in the cirrhotic patients, as demonstrated by their higher clamp insulin levels. The minimal model assumes that the action of insulin is linear over the physiological range of insulin concentrations. While this may be correct in normal and insulin-resistant subjects without liver disease, this assumption may no longer be valid at the insulin levels seen in cirrhotic patients during the FSIGT; the effect would be to overestimate the degree of insulin resistance.

It would appear that as in Type 2 diabetes, overt diabetes develops in those cirrhotic patients who have a marked impairment of insulin secretion in addition to insulin insensitivity. One possibility is that a genetic factor, present in both Type 2 diabetic patients and those cirrhotic patients who develop diabetes, is responsible for the impairment of insulin secretion, although cirrhotic patients with a family history of diabetes were excluded in our study. Further work is needed to test this hypothesis, and to determine whether the reduction in $\mathrm{S}_{\mathrm{G}}$ in diabetic cirrhotic patients is due to an impairment of HGO suppression or an impairment of the mass action effect of glucose on tissue glucose uptake.

Acknowledgements. The study was supported by the British Diabetic Association and the Nuffield Foundation. We thank Dr. P.Home, Newcastle-upon-Tyne, UK for the C-peptide measurements.

\section{References}

1. Megyesi C, Samols E, Marks V (1967) Glucose tolerance and diabetes in chronic liver disease. Lancet II: 1051-1056

2. Conn HO, Schreiber W, Elkington SG (1971) Cirrhosis and diabetes. II. Association of impaired glucose tolerance with portal-systemic shunting in Laennec's cirrhosis. Dig Dis 16:227239

3. Kruszynska YT, Home PD, McIntyre N (1991) The relationship between insulin sensitivity, insulin secretion and glucose tolerance in cirrhosis. Hepatology 14: 103-111

4. Weir GC (1982) Non-insulin dependent diabetes mellitus: interplay between B cell inadequacy and insulin resistance. Am J Physiol 73: 461-464

5. Bergman RN (1989) Toward physiological understanding of glucose tolerance. Minimal model approach. Diabetes 38: 15121527

6. Ader M, Bergman RN (1987) Insulin sensitivity in the intact organism. In: Alberti KGMM, Home PD, Taylor R (eds) Bailliere's clinics in endocrinology and metabolism. Techniques for metabolic investigation in man, vol 1, part 1 . Bailliere Tindall, London, pp 879-910

7. Bergman RN, Ider YZ, Bowden CR, Cobelli C (1979) Quantitative estimation of insulin sensitivity. Am J Physiol 236: E667E677

8. DeFronzo RA, Tobin JD, Andres R (1979) Glucose clamp technique: a method for quantifying insulin secretion and resistance. Am J Physiol 237: E214-E223 
9. Bergman RN, Prager R, Volund A, Olefsky JM (1987) Equivalence of the insulin sensitivity index in man derived by the minimal model method and the euglycaemic glucose clamp. J Clin Invest 79: 790-800

10. Finegood DT, Hramiak IM, Dupre J (1990) A modified protocol for estimation of insulin sensitivity with the minimal model of glucose kinetics in patients with insulin-dependent diabetes. J Clin Endocrinol Metab 70: 1538-1549

11. Ward GM, Weber KM, Walters IM et al. (1991) A modified minimal model analysis of insulin sensitivity and glucose mediated glucose disposal in insulin-dependent diabetes. Metabolism 40: 4-9

12. Petrides AS, Schulze-Berge D, Matthews D, Strohmeyer G (1991) The pathogenesis of manifest diabetes mellitus in cirrhosis. Hepatology 14: 144A (Abstract)

13. Yang YJ, Youn JH, Bergman RN (1987) Modified protocols insulin sensitivity estimation using the minimal model. Am J Physiol 253: E595-E602

14. Soeldner JS, Sloane D (1965) Critical variables in the radioimmunoassay of serum insulin using the double-antibody technique. Diabetes 14: 771-779

15. Heding LG (1975) Radioimmunological determination of human C-peptide in serum. Diabetologia 11:541-548

16. Bergman RN, Bucolo RJ (1974) Interaction of insulin and glucose in the control of hepatic glucose balance. Am J Physiol 227: 1314-1322

17. Bucolo RJ, Bergman RN, Marsh DJ, Yates FE (1974) Dynamics of glucose autoregulation in the isolated, blood-perfused canine liver. Am J Physiol 227: 209-217

18. Kruszynska YT, Home PD, Alberti KGMM (1986) In vivo regulation of liver and skeletal muscle glycogen synthase activity by glucose and insulin. Diabetes 35: 662-667

19. Yki-Jarvinen H, Mott D, Young AA, Stone K, Bogardus C (1987) Regulation of glycogen synthase and phosphorylase activities by glucose and insulin in human skeletal muscle. J Clin Invest 80: 95-100

20. Insel PA, Liljenquist JE, Tobin JD et al. (1975) Insulin control of glucose metabolism in man. J Clin Invest 55: 1057-1066

21. Sherwin RS, Kramer KJ, Tobin JD et al. (1974) A model of the kinetics of insulin in man. J Clin Invest 53: 1481-1492

22. Cerasi E, Luft R (1967) The plasma insulin response to glucose infusion in healthy subjects and in diabetes mellitus. Acta Endocrinol 55:278-304

23. Brunzell JD, Robertson RP, Lerner RL et al. (1976) Relationships between fasting plasma glucose levels and insulin secretion during intravenous glucose tolerance tests. J Clin Endocrinol Metab 42: 222-229

24. Nygren A, Adner N, Sundblad L, Weichel KL (1985) Insulin uptake by the human alcoholic cirrhotic liver. Metabolism 34: 48 52

25. Polonsky KS, Rubenstein AH (1984) C-peptide as a measure of the secretion and hepatic extraction of insulin: pitfalls and limitations. Diabetes 33: 486-494

26. Kruszynska YT, Munro J, Home PD; McIntyre N (1992) Twenty four hour C-peptide and insulin secretion rates and diurnal profiles of glucose, lipids and intermediary metabolites in cirrhosis. Clin Sci 83: 597-605

27. Tillil H, Shapiro ET, Miller MA et al. (1988) Dose-dependent effects of oral and intravenous glucose on insulin secretion and clearance in normal humans. Am J Physiol 254: E349-E357

28. Robertson RP (1989) Type 2 diabetes, glucose "non-sense", and islet desensitisation. Diabetes 38: 1501-1505

29. Varsano-Aharon N, Echemendia E, Yalow RS, Berson SA (1970) Early insulin responses to glucose and to tolbutamide in maturity-onset diabetes. Metabolism 19: 409-417

30. Ward WK, Beard JC, Porte D (1986) Clinical aspects of islet $\mathrm{B}$-cell function in non-insulin dependent diabetes mellitus. Diabetes Metab Rev 2: 297-313
31. Vetter D, Fratte S, Winiszewski P et al. (1990) Consequences de l'hyperglycemie sur le metabolisme glucidique et azote dans la cirrhose: exploration par une epreuve de clamp hyperglycemique. Gastroenterol Clin Biol 14: 483 491

32. Cobelli C, Pacini G, Toffolo G, Sacca L (1986) Estimation of insulin sensitivity and glucose clearance from minimal model: new insights from labelled IVGTT. Am J Physiol 250: E591-E598

33. Bourey RE, Koranyi L, James DE, Mueckler M, Permutt MA (1990) Effects of altered glucose homeostasis on glucose transporter expression in skeletal muscle of the rat. J Clin Invest 86: $542-547$

34. Seltzer H, Allen W, Herron AL, Brennan MT (1967) Insulin secretion in response to glycaemic stimulus: relation of delayed initial release to carbohydrate intolerance in mild diabetes mellitus. J Clin Invest 46:323-335

35. Luzi L, DeFronzo RA (1989) Effect of loss of first-phase insulin secretion on hepatic glucose production and tissue glucose disposal in humans. Am J Physiol 257: E241-E246

36. Bruce DG, Chisholm DJ, Storlien LH, Kraegen EW (1988) Physiological importance of deficiency in early prandial insulin secretion in non-insulin dependent diabetes. Diabetes 37: 736744

37. Mitrakou A, Kelley D, Mokan M et al. (1992) Role of reduced suppression of glucose production and diminished early insulin release in impaired glucose tolerance. $\mathrm{N}$ Engl J Med 326: 22-29

38. Lerner RL, Porte D (1972) Acute and steady-state insulin responses to glucose in non-obese diabetic subjects. J Clin Invest 51: 1624-1631

39. Doberne L, Greenfield MS, Schulz B, Reaven GM (1981) Enhanced glucose utilisation during prolonged glucose clamp studies. Diabetes 30: 829-835

40. Sacca L, Cicala M, Trimarco B, Ungaro B, Vigorito C(1982) Differential effects of insulin on splanchnic and peripheral glucose disposal after an intravenous glucose load in man. J Clin Invest 70: $117-126$

41. DeFronzo RA (1987) The triumvirate: B-cell, muscle, liver. Diabetes 37: 667-687

42. Yang YJ, Hope ID, Ader M, Bergman RN (1989) Insulin transport across capillaries is rate limiting for insulin action in dogs. J Clin Invest 84: 1620-1628

43. Kruszynska YT, Williams N, Perry M, Home PD (1988) The relationship between insulin sensitivity and skeletal muscle enzyme activities in hepatic cirrhosis. Hepatology 8: 1615-1619

44. Prager R, Wallace P, Olefsky JM (1986) In vivo kinetics of insulin action on peripheral glucose disposal and hepatic glucose output in normal and obese subjects. J Clin Invest 78: 472-481

45. Proietto J, Alford FP, Dudley FJ (1980) The mechanism of the carbohydrate intolerance in cirrhosis. J Clin Endocrinol Metab 51: $1030-1036$

46. Cavallo-Perin P, Cassader M, Bozzo Cet al. (1985) Mechanism of insulin resistance in human liver cirrhosis: evidence of a combined receptor and postreceptor defect. J Clin Invest 75: 16591665

Received: 28 April 1992 and in revised form:29 September 1992

Dr. Y. T. Kruszynska

Department of Medicine

Royal Free Hospital

Pond Street

London NW3 2QG

UK 